\title{
Safety and efficacy of self-expandable Evolut R vs. balloon-expandable Sapien 3 valves for transcatheter aortic valve implantation: A systematic review and meta-analysis
}

\author{
CHENGLIN HE $^{1}$, LANG XIAO ${ }^{2}$ and JUNLI LIU ${ }^{3}$ \\ ${ }^{1}$ Department of Cardiovascular Medicine, Hanchuan People's Hospital; ${ }^{2}$ Department of Haematology, \\ Hanchuan Hospital of Traditional Chinese Medicine; ${ }^{3}$ Department of Critical Care Medicine, \\ Hanchuan People's Hospital, Hanchuan, Hubei 431600, P.R. China
}

Received July 31, 2019; Accepted September 9, 2019

DOI: 10.3892/etm.2019.8000

\begin{abstract}
The aim of this study was to systematically search literature and conduct a meta-analysis comparing the clinical efficacy and safety of Evolut R and Sapien 3 valves for transcatheter aortic valve implantation (TAVI). The PubMed, Biomed Central, Scopus, Cochrane library and Google scholar databases were searched for articles published up to June, 2019. A total of 5 studies were included. In total, 795 patients underwent TAVI with Evolut R, while 665 patients received the Sapien 3 valve in the included studies. Overall device success with Evolut R was 95.7\% and with Sapien 3 was 94.2\%. Pooled data indicated no significant differences between the 2 valves (OR, 1.12; 95\% CI, $0.66-1.89 ; \mathrm{P}=0.68 ; \mathrm{I}^{2}=0 \%$ ). No significant differences were observed in the incidence of none to mild paravalvular leakage between the 2 groups (OR, 1.71; 95\% CI, 0.83-3.54; $\mathrm{P}=0.14$; $\left.\mathrm{I}^{2}=0 \%\right)$. Both mean [random; mean difference $(\mathrm{MD})=-3.96$; 95\% CI, -4.61 to $\left.-3.31 ; \mathrm{P}<0.00001, \mathrm{I}^{2}=0 \%\right]$ and peak (random; $\mathrm{MD}=-6.85 ; 95 \% \mathrm{CI},-8.22$ to $-5.48 ; \mathrm{P}<0.00001, \mathrm{I}^{2}=0 \%$ ) aortic valve gradients were significantly lower with Evolut R. No significant differences were observed in the 30-day mortality (OR, 1.32; 95\% CI, $0.45-3.87 ; \mathrm{P}=0.62 ; \mathrm{I}^{2}=0 \%$ ) or 30 -day stroke outcomes (OR, 0.76; 95\% CI, 0.32-1.81; $\mathrm{P}=0.54 ; \mathrm{I}^{2}=0 \%$ ) between the 2 devices. On the whole, the findings of this study indicate that Evolut $\mathrm{R}$ and Sapien 3 valves may be comparable in terms of device success and short-term complications. The differences between the 2 devices for post-operative moderate to severe paravalvular leak and permanent pacemaker implantation remain unclear. There is thus a need for a large multi-center randomized controlled trial to provide stronger evidence on this subject.
\end{abstract}

Correspondence to: Dr Junli Liu, Department of Critical Care Medicine, Hanchuan People's Hospital, Te 1 People's Avenue, Hanchuan, Hubei 431600, P.R. China

E-mail: hechenglin2012@sina.com

Key words: transcatheter aortic valve implantation, aortic stenosis, clinical outcomes, self-expanding valve, balloon-expandable valve

\section{Introduction}

Transcatheter aortic valve implantation (TAVI) is the recommended treatment option in patients with severe aortic stenosis considered inoperable or at high surgical risk (1). The balloon-expandable Edward Sapien (Edwards Lifesciences) and the self-expandable Medtronic CoreValve (Medtronic) are the most commonly used aortic valves from the early generation (2). Studies have shown similar outcomes with both valves, in terms of mortality, rate of stroke and post-operative functional status $(3,4)$. However, one of the major shortcomings of these early generation valves is the presence of paravalvular leakage, which results in moderate-severe aortic regurgitation and has been associated with an increased late mortality $(5,6)$. With ongoing research and development with respect to TAVI, two competing newer generation valves, the Sapien 3 (Edwards Lifesciences) and CoreValve Evolut R (Medtronic) have been introduced and are widely used in the Unites States (7). The Sapien 3 is a balloon-expandable valve, comprising a nickel cobalt chromium frame, tri-leaflet bovine pericardial tissue valve and a polyethylene terephthalate sealing skirt. The Evolut R, is a self-expanding valve comprising a tri-leaflet porcine pericardial tissue valve mounted within a compressible Nitinol frame (8). Both have been designed to further reduce the rate of paravalvular leakage, conduction abnormalities and vascular complications associated with TAVI $(9,10)$.

Schulz et al (11), in a single center cohort study, demonstrated a reduced rate of more-than-mild paravalvular regurgitation and a greater device success with Evolut R, as compared to the earlier generation CoreValve. Similarly, the results of the study by Nijhoff et al (12) indicated the superiority of Sapien 3 over its predecessor, in terms of improved valve patency and increased transfemoral access safety. With both the new-generation valves becoming increasingly popular, it is important to determine whether any one of the valve results in superior outcomes over the other. While studies have compared the efficacy and safety of Evolut R vs. Sapien 3, there is a lack of level 1 evidence in the form of a systematic review and meta-analysis. Hence, the aim of this study was to systematically search the literature and conduct a meta-analysis comparing the clinical efficacy and safety of Evolut R and Sapien 3 valves for TAVI. 


\section{Data and methods}

This systematic review and meta-analysis were conducted in accordance with the Meta-analyses Of Observational Studies in Epidemiology (MOOSE) checklist (13). The research question to be answered was the following: Whether there is any difference in the clinical efficacy and safety profiles of Evolut R and Sapien 3 valves for TAVI.

Search strategy. An electronic search of the PubMed, Biomed Central, Scopus, Cochrane library and Google scholar databases was performed for articles published up to June, 2019. Free text keywords and MeSH terms were used in various combinations. Search keywords included: 'Transcatheter aortic valve SAPIEN 3', 'transcatheter aortic valve Evolut R', 'TAVI', 'transcatheter aortic valve implantation', 'self-expandable aortic valve' OR 'balloon expandable aortic valve'. The references of included studies and review articles on the subject were hand searched for the identification of any additional studies.

Eligibility criteria. We searched for pertinent studies comparing the clinical efficacy and safety of Evolut R and Sapien 3 valves for TAVI. No restriction was placed on the type of study. Studies were included if they met the following specifications: i) Compared outcomes following TAVI with Evolut R and Sapien 3 valves; and ii) predominant mode of TAVI was trans-femoral route $(>80 \%)$. The outcome assessment had to include any one of the following variables: Mortality, stroke, paravalvular leakage, major vascular complications and bleedings, and pacemaker implantation. Studies excluded were the following: i) Studies not reporting separate outcome data for Evolut R and Sapien 3 valves; ii) duplicate reports; iii) case series and case reports with $<10$ patients; and iv) non-English language studies and animal studies.

Data extraction and quality assessment. Two independent reviewers performed the literature search. Following the removal of duplicates, studies were scrutinized by their title and abstracts to determine whether they met the inclusion criteria. The full-texts of the selected articles were then scanned for inclusion in the review. Any discrepancies were resolved by discussion. Data were extracted from the included trials by 2 independent reviewers using an abstraction form. The following details were sourced: Authors, publication year, sample size, demographic and baseline data of participants, TAVI procedural details, and outcomes assessed. Two reviewers independently assessed the risk of bias using the Newcastle-Ottawa Scale for non-randomized studies (14).

Statistical analysis. Outcome data are presented as either the means \pm standard deviation (SD) for continuous variables or as the number of events per group for categorical variables. Data extracted were entered into Review Manager [RevMan, version 5.3; Nordic Cochrane Centre (Cochrane Collaboration), Copenhagen, Denmark, 2014] for meta-analysis. Considering the heterogeneity amongst studies, a random-effects model was used to calculate the pooled effect size. Categorical data were summarised using the Mantel-Haenszel odds ratios (OR) and 95\% confidence intervals (CI). The mean difference (MD) with
95\% CI was used to pool continuous variables. Heterogeneity was calculated using the $\mathrm{I}^{2}$ statistic. $\mathrm{I}^{2}$ values of $25-50 \%$ represented low, values of $50-75 \%$ medium and $>75 \%$ represented substantial heterogeneity. The influence of each study on the pooled effect size was analyzed using a sensitivity analysis. Using the one-study-out method, we assessed whether deleting each individually would significantly change the pooled results of the meta-analysis.

\section{Results}

The search results are presented in Fig. 1. A total of seven articles were analyzed by their full text. Two studies were excluded. In one study (15), the outcome data for Evolut R and Sapien 3 valves were not presented separately. Another study (16) examined gender-based differences in outcomes, in a cohort of Evolut R and Sapien 3 TAVI patients without any comparison between the 2 valves. A total of 5 studies $(8,17-20)$ met the inclusion criteria and were included in the systematic review and meta-analysis. No randomized controlled trials were available for inclusion. Four $(8,18-20)$ were retrospective cohort studies, while one was a prospective study (17). The prospective study (17) compared outcomes between Evolut R and Sapien 3 valves in patients with large annuli $(\geq 26 \mathrm{~mm})$. None of the remaining studies used any exclusion criteria based on any patient characteristic.

Baseline and procedural characteristics. A total of 795 patients underwent TAVI with Evolut R, while 665 patients received the Sapien 3 valve in the included studies. The baseline characteristics of the study participants are presented in Table I. With the exception of one study (20), there were minimal differences between the baseline characteristics of the 2 groups. In the study by Finkelstein et al (20), the groups were not matched for age, sex, Society of Thoracic Surgeons (STS) score, hyperlipidemia, ischemic heart disease, New York Heart Association (NYHA) classification and left ventricular ejection fraction (LVEF). The procedural details of the included studies are presented in Table II. Two studies $(17,18)$ utilized transfemoral access in all patients, while in the remaining studies, the transfemoral route was used in $>89 \%$ of the study participants. One study (17) compared the $34 \mathrm{~mm}$ Evolut $\mathrm{R}$ valve with $29 \mathrm{~mm}$ Sapien 3 valve. Multiple different-sized valves were used in the remaining studies. The authors' assessment of the quality of the included studies is presented in Data S1.

\section{Outcomes}

Device success and post-procedural echocardiogram outcomes. Data on the outcomes of the included studies are presented in Table III. Valve Academic Research Consortium-2 consensus document (VARC-2) (21)-defined device success was reported in all 5 studies. The overall device success with Evolut R was 95.7\% (761/795) and that with Sapien 3 was 94.2\% (627/665). Pooled data indicated no significant differences between the 2 valves (OR, 1.12, 95\% CI, 0.66-1.89; $\mathrm{P}=0.68$; $\mathrm{I}^{2}=0 \%$ ) (Fig. 2). Data on post-procedural LVEF were available from 3 studies. Meta-analysis indicated no differences between the 2 groups (random; $\mathrm{MD}=-0.29 ; 95 \% \mathrm{CI},-1.74$ to 1.17; $\mathrm{P}=0.70 ; \mathrm{I}^{2}=0 \%$ ) (Fig. 3A). The incidence of none to mild 


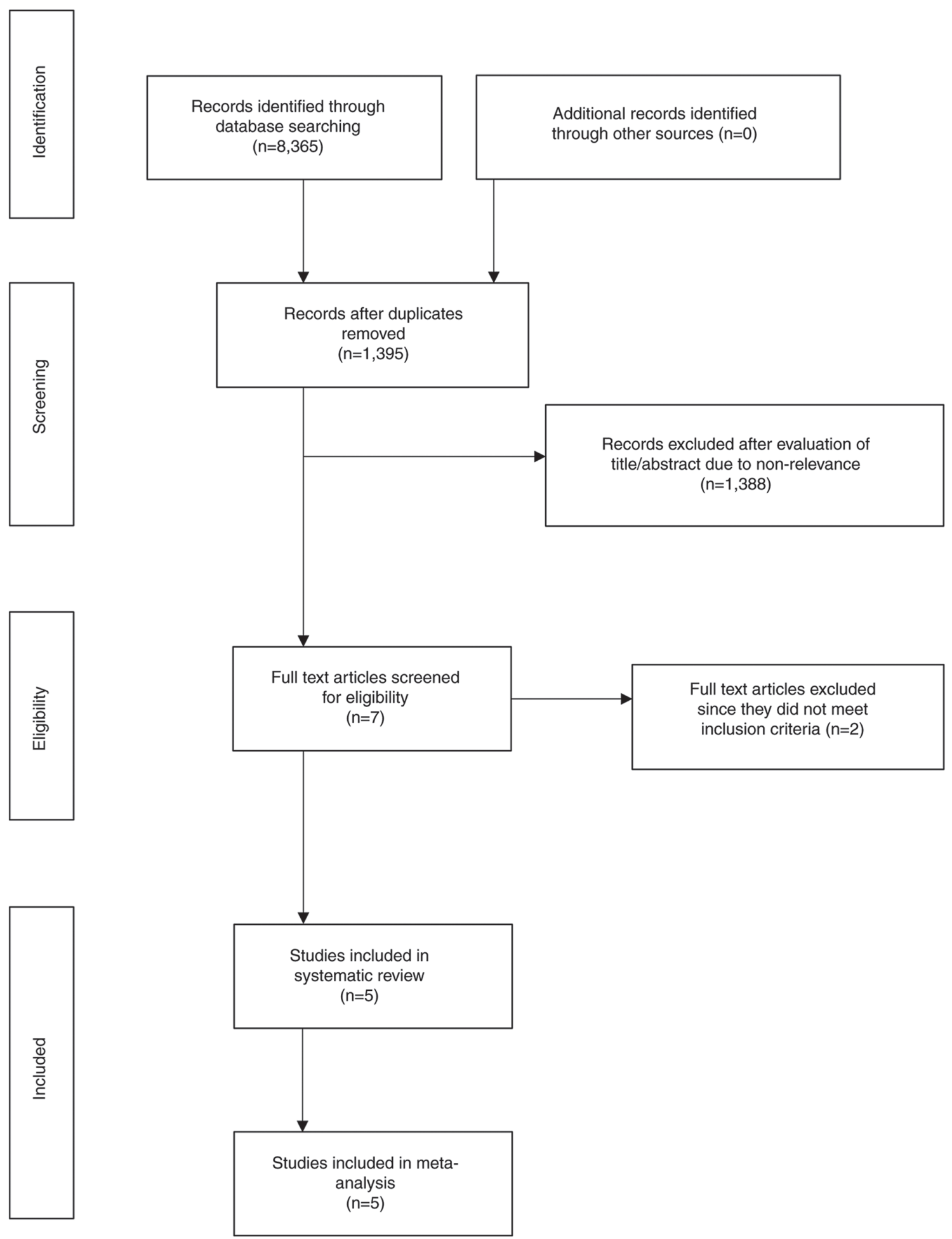

Figure 1. Search outcomes of the study.

paravalvular leakage did not differ between the 2 groups (OR, 1.71; 95\% CI, 0.83-3.54; $\mathrm{P}=0.14 ; \mathrm{I}^{2}=0 \%$ ) (Fig. 3B). In total, $3.3 \%$ (26/794) patients had more than moderate paravalvular regurgitation with Evolut R, while the same was reported in $1.4 \%(9 / 665)$ patients with Sapien 3. Pooled analysis did not demonstrate any statistically significant differences (OR, 1.95; 95\% CI, 0.62-6.18; $\mathrm{P}=0.25 ; \mathrm{I}^{2}=28 \%$ ) (Fig. 3C). Both the mean (random; $\mathrm{MD}=-3.96 ; 95 \% \mathrm{CI},-4.61$ to $-3.31 ; \mathrm{P}<0.00001$, $\mathrm{I}^{2}=0 \%$ ) (Fig. 3D) and peak (random; $\mathrm{MD}=-6.85 ; 95 \% \mathrm{CI}$,
-8.22 to $-5.48 ; \mathrm{P}<0.00001, \mathrm{I}^{2}=0 \%$ ) (Fig. $3 \mathrm{E}$ ) aortic valve gradients were significantly lower with Evolut R.

Immediate post-operative complications. In total, $2.28 \%$ $(5 / 219)$ of the patients had a life-threatening bleed with Evolut R, while 2.2\% (8/362) had the same experience with Sapien 3; no statistically significant differences were observed (OR, 1.16; 95\% CI, 0.34-3.93; P=0.82; $\mathrm{I}^{2}=0 \%$ ) (Fig. 4A). Data on major vascular complication was reported by 3 studies. With 5/219 events (2.3\%) with Evolut R and 10/362 events 


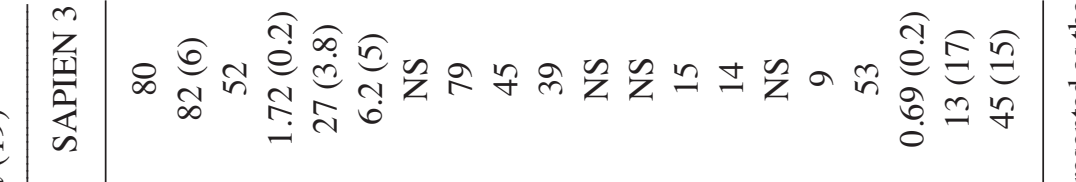
$\stackrel{\simeq}{\Xi}$

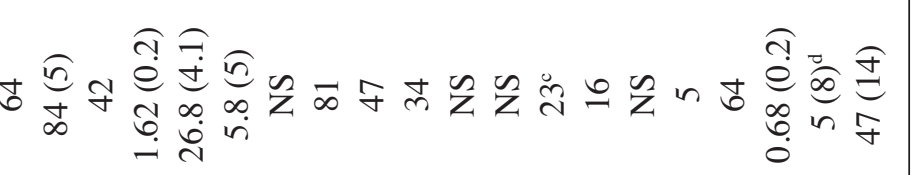

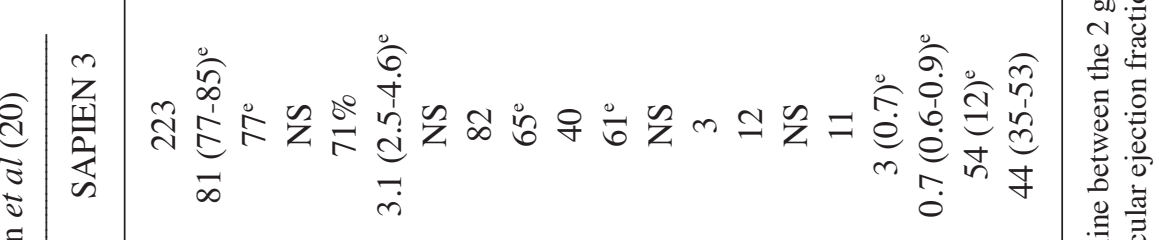

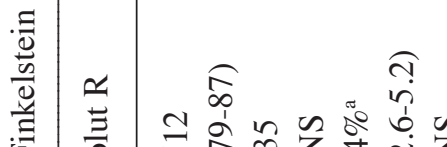

$\widehat{\infty} \widehat{\rho}$

节

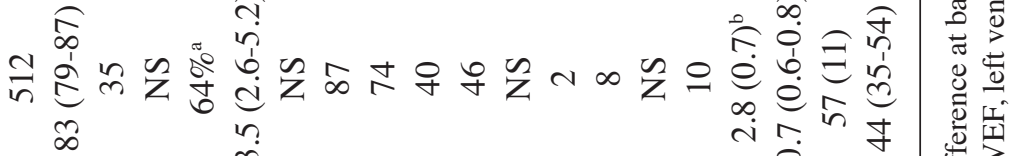

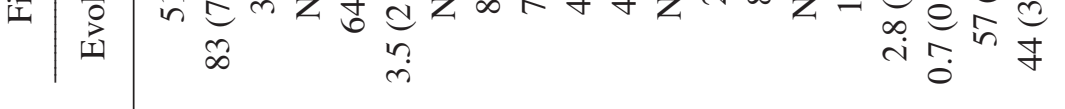

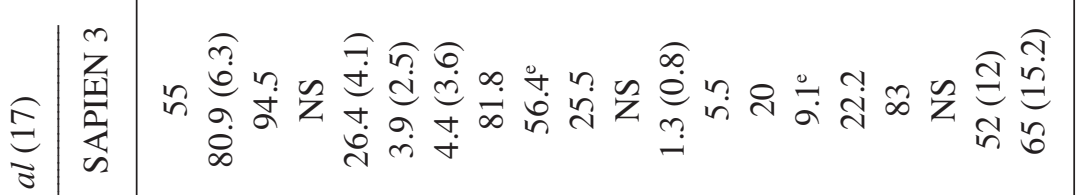

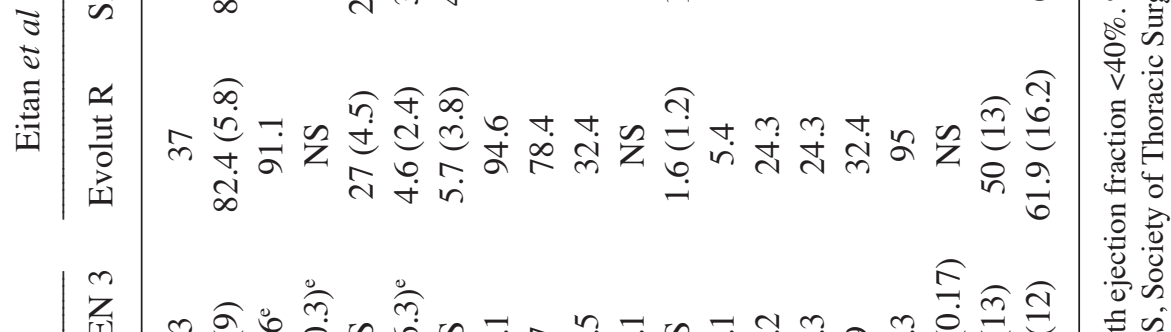

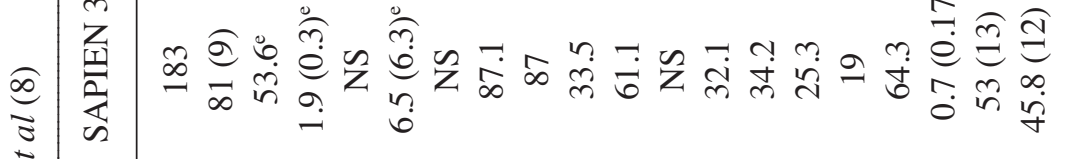

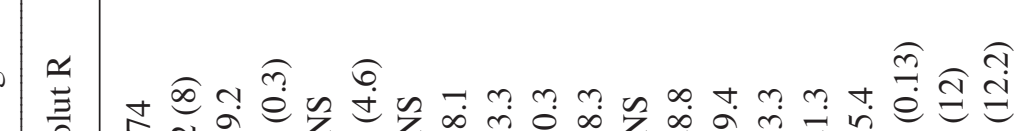

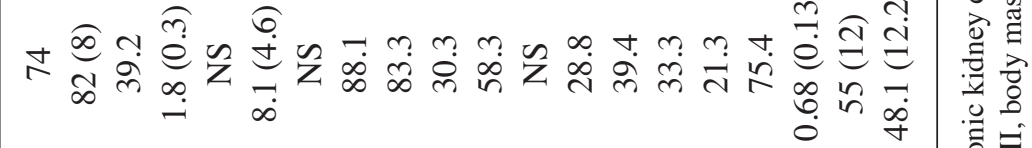

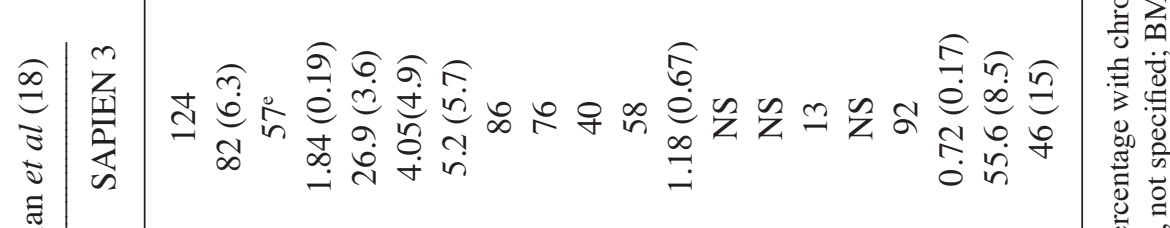

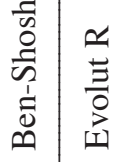

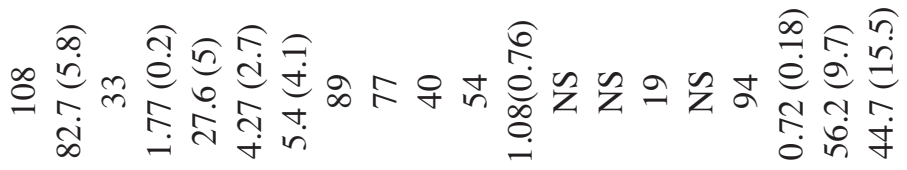

ङू

这

苛

这

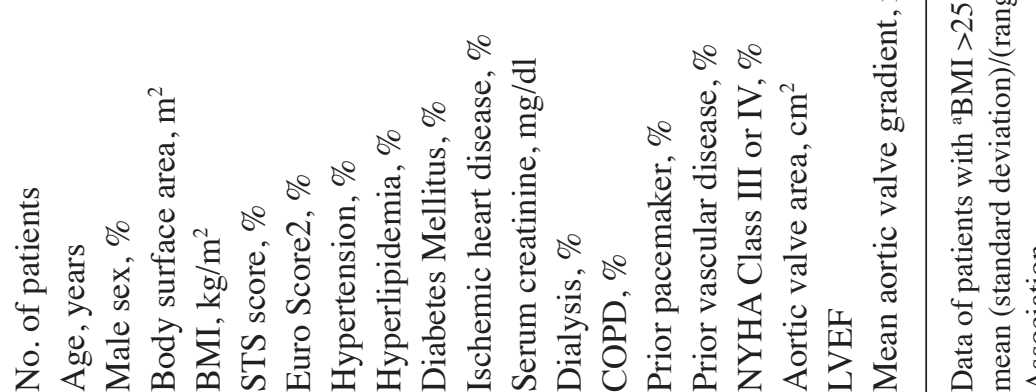


(2.8\%) with Sapien 3 , there were no statistically significant differences between the 2 groups (OR, 0.94; 95\% CI, 0.32-2.74; $\left.\mathrm{P}=0.91 ; \mathrm{I}^{2}=0 \%\right)($ Fig. 4B). A greater percentage [18\% (133/738)] of patients underwent pacemaker implantation following TAVI with Evolut R, as compared to 12\% (72/594) with Sapien 3. This difference, however, did not reach statistical significance (OR, 1.57, 95\% CI, 0.99-2.49, P=0.06; $\mathrm{I}^{2}=40 \%$ ) (Fig. 4C). Pooled data from 3 studies on acute kidney injury with 13/219 (5.9\%) events with Evolut R and 19/362 (5.2\%) events with Sapien 3, did not reveal any significant differences between the 2 groups (OR, 1.00; 95\% CI, 0.47-2.14; $\mathrm{P}=1.00 ; \mathrm{I}^{2}=0 \%$ ) (Fig. 4D). Data on stroke and immediate mortality were reported by 3 studies. With 5 cases of stroke in 219 patients $(2.2 \%)$ in the Evolut R group and 5 cases of stroke in 362 patients (1.4\%) in the Sapien 3 group, no statistically significant differences were noted (OR, 1.72; 95\% CI, 0.41-7.26; $\mathrm{P}=0.46 ; \mathrm{I}^{2}=0 \%$ ) (Fig. 4E). Similarly, with 6 deaths out of the 657 patients $(0.9 \%)$ with Evolut R and 1 death out of the 402 patients $(0.2 \%)$ with Sapien 3 , the pooled analysis did not reveal any significant difference (OR, 2.15; 95\% CI, 0.36-12.89, P=0.40; $\mathrm{I}^{2}=0 \%$ ) (Fig. 4F).

30-day outcomes. At 30 days, there were 11 deaths out of the 694 patients (1.6\%) with Evolut $R$ and 6 deaths out of the 530 patients (1.1\%) with Sapien 3. The difference was not statistically significant $\left(\mathrm{OR}, 1.32 ; 95 \% \mathrm{CI}, 0.45-3.87 ; \mathrm{P}=0.62 ; \mathrm{I}^{2}=0 \%\right)$ (Fig. 5A). Similarly, no differences was observed in the 30-day stroke outcomes between the 2 groups (OR, 0.76; 95\% CI, $0.32-1.81 ; \mathrm{P}=0.54 ; \mathrm{I}^{2}=0 \%$ ) (Fig. $5 \mathrm{~B}$ ). In total, 12 patients had a life-threatening bleed out of 684 patients in the Evolut $\mathrm{R}$ group (1.8\%), while 9 of the 427 patients experienced the same with Sapien 3 (2.1\%). Meta-analysis indicated no statistically significant differences (OR, 0.78; 95\% CI, 0.31-1.96; $\mathrm{P}=0.60$; $\mathrm{I}^{2}=2 \%$ ) (Fig. 5C). In total, 3.8\% patients (26/684) had major vascular complication with Evolut R, while 4.4\% (19/427) had the same experience with Sapien 3. Pooled analysis failed to demonstrate any significant difference (OR, 0.91; 95\% CI, 0.49-1.68; $\mathrm{P}=0.75 ; \mathrm{I}^{2}=0 \%$ ) (Fig. 5D).

Sensitivity analysis. A sensitivity analysis was carried out wherein each study was sequentially removed from the meta-analysis. It was found that when the results of the study by Ben-Shoshan et al (18) were removed, overall pooled estimate for pace-maker implantation became statistically significant in favor of Sapien 3 (OR, 1.92; 95\% CI, 1.02-3.60; $\mathrm{P}=0.04 ; \mathrm{I}^{2}=47 \%$ ) (Fig. 6A). In addition, the results for more than moderate paravalvular regurgitation became significant in favor of Sapien 3 (OR, 2.95; 95\% CI, 1.15-7.53; $\mathrm{P}=0.02$; $\mathrm{I}^{2}=0 \%$ ) (Fig. 6B). No other outcomes were changed following the removal of any of the 5 included studies. Sensitivity analysis with fixed model also did not influence any of the outcomes.

\section{Discussion}

The primary objective of this study was to compare the clinical outcomes and safety profile of the newer generation Evolut R and Sapien 3 valves. An important criteria for such a comparison is to have baseline similarity between the 2 groups. Our literature search revealed only 5 studies reporting head-to-head comparison of the 2 devices. With the exception of one study (19), there were some baseline 


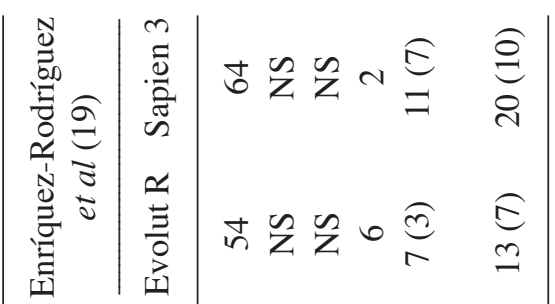

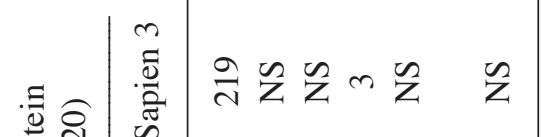

言忌

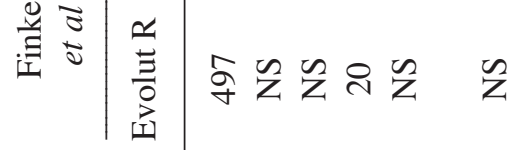

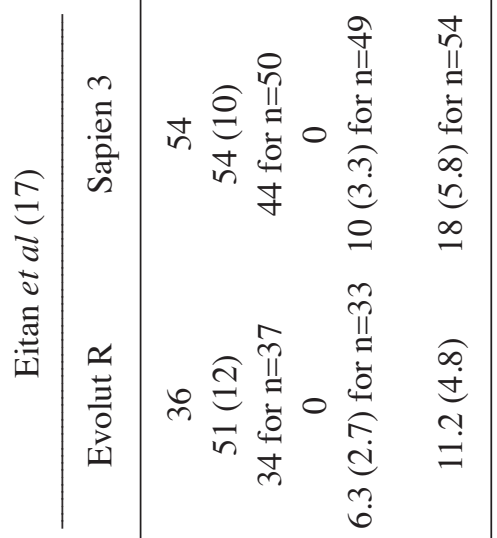

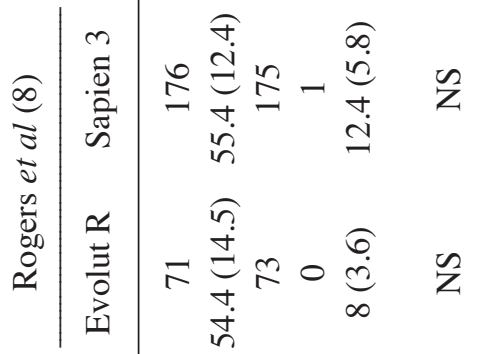

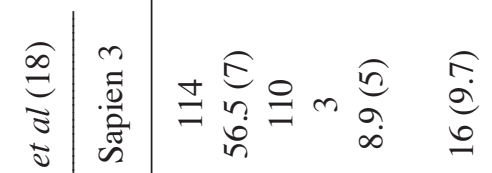

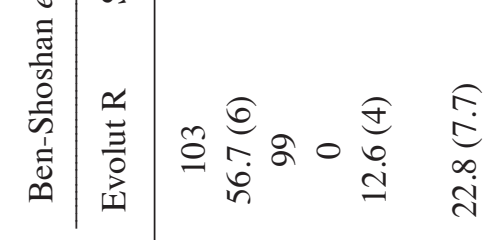

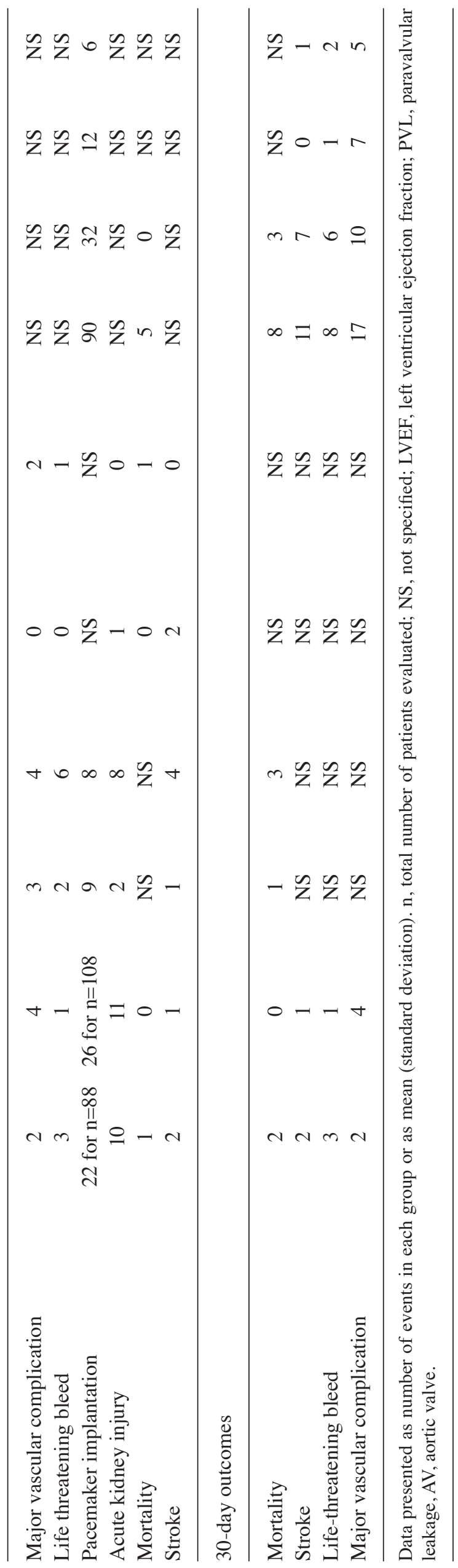




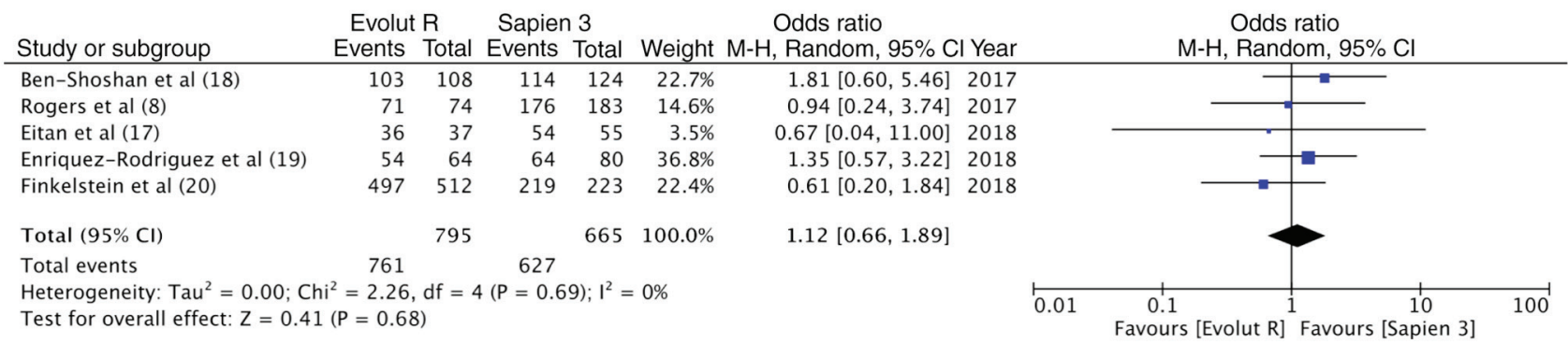

Figure 2. Forrest plot of device success.

\begin{tabular}{|c|c|c|c|c|c|c|c|c|c|}
\hline & & volut $F$ & & & pien & & & Mean difference & \\
\hline Study or subgroup & Mean & SD & Total & Mean & SD & Total & Weight & IV, Random, 95\% Cl & Year \\
\hline Ben-Shoshan et al (18) & 56.7 & 6 & 108 & 56.5 & 7 & 124 & $75.4 \%$ & $0.20[-1.47,1.87]$ & 2017 \\
\hline Rogers et al (8) & 54.4 & 14.5 & 74 & 55.4 & 12.4 & 183 & $14.9 \%$ & $-1.00[-4.76,2.76]$ & 2017 \\
\hline Eitan et al (17) & 51 & 12 & 37 & 54 & 10 & 55 & $9.6 \%$ & $-3.00[-7.68,1.68]$ & 2018 \\
\hline Total $(95 \% \mathrm{Cl})$ & & & 219 & & & 362 & $100.0 \%$ & $-0.29[-1.74,1.17]$ & \\
\hline
\end{tabular}

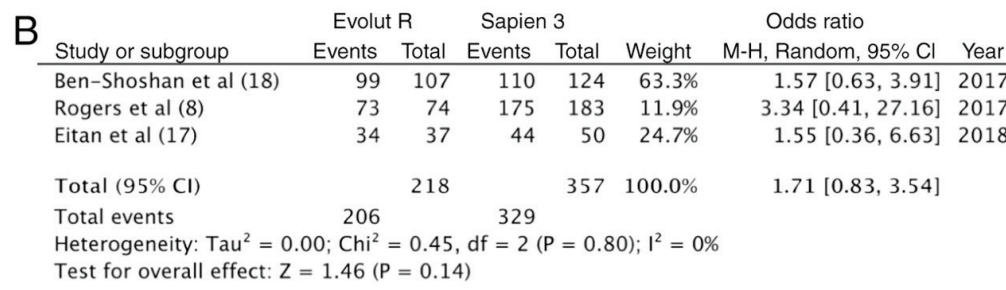

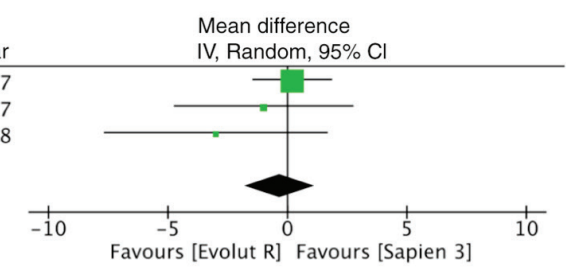

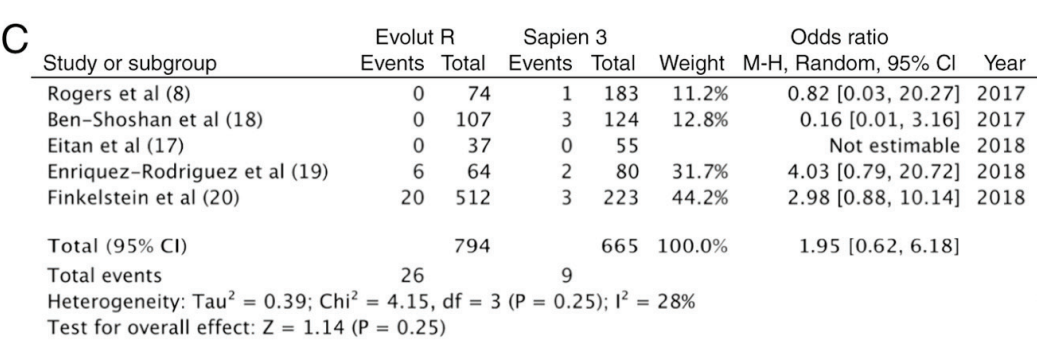

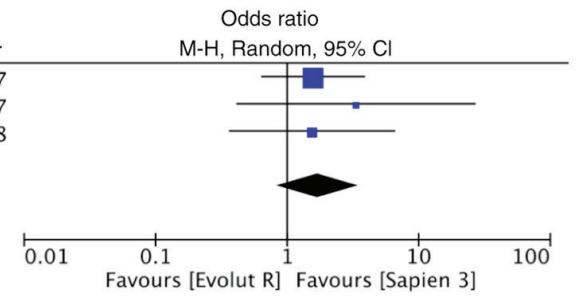

\begin{tabular}{|c|c|c|c|c|c|c|c|c|c|}
\hline \multirow[b]{2}{*}{ Study or subgroup } & \multicolumn{3}{|c|}{ Evolut R } & \multicolumn{3}{|c|}{ Sapien 3} & \multicolumn{3}{|c|}{ Mean difference } \\
\hline & Mean & SD & Total & Mean & SD & Total & Weight & IV, Random, $95 \% \mathrm{Cl}$ & Year \\
\hline Ben-Shoshan et al (18) & 16 & 9.7 & 107 & 22.8 & 7.7 & 124 & $36.2 \%$ & $-6.80[-9.08,-4.52]$ & 2017 \\
\hline Eitan et al (17) & 11.2 & 4.8 & 37 & 18 & 5.8 & 54 & $39.4 \%$ & $-6.80[-8.99,-4.61]$ & 2018 \\
\hline Enriquez-Rodriguez et al (19) & 13 & 7 & 64 & 20 & 10 & 80 & $24.4 \%$ & $-7.00[-9.78,-4.22]$ & \\
\hline Total $(95 \% \mathrm{Cl})$ & & & 208 & & & 258 & $100.0 \%$ & $-6.85[-8.22,-5.48]$ & \\
\hline
\end{tabular}

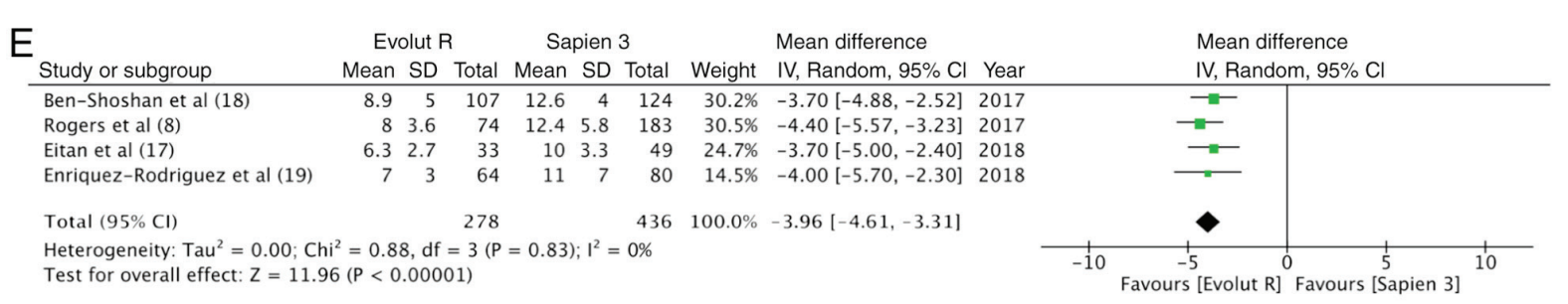

Figure 3. (A) Forrest plot of deft ventricular ejection fraction. (B) Forrest plot of paravalvular leakage (not mild). (C) Forrest plot of paravalvular leakage (moderate to severe). (D) Forrest plot of mean aortic valve gradient. (E) Forrest plot of peak aortic valve gradient.

differences between the 2 groups, which could have affected the results of this meta-analysis. Mindful of this disparity, the primary findings of this study can be summarized as follows: i) VARC-2 success rates with both devices seem to be similar; ii) there seem to be no difference in the incidence of mild paravalvular leak with the 2 valves; however, evidence regarding moderate to severe paravalvular leak is not clear; iii) aortic valve gradients are significantly lower with Evolut R; iv) there seems to be no difference in the short-term safety profile of the 2 devices. 


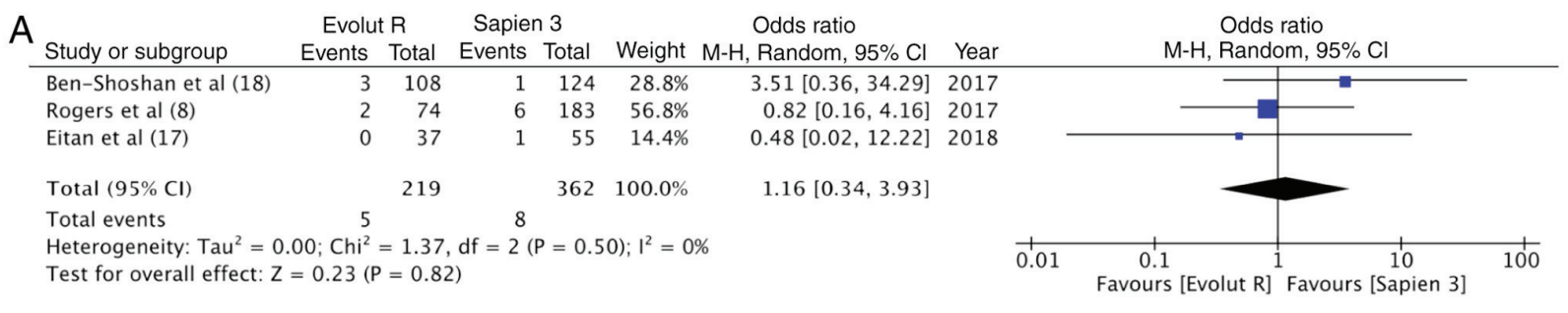

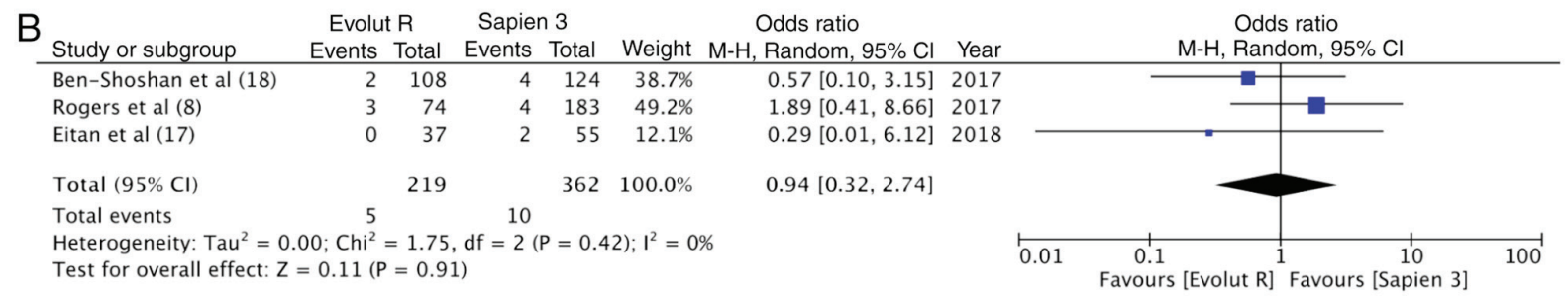

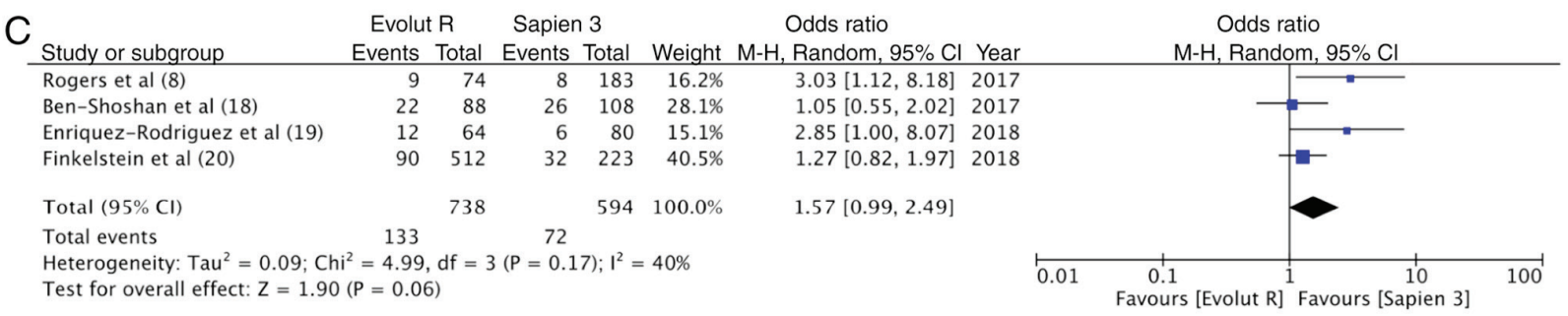

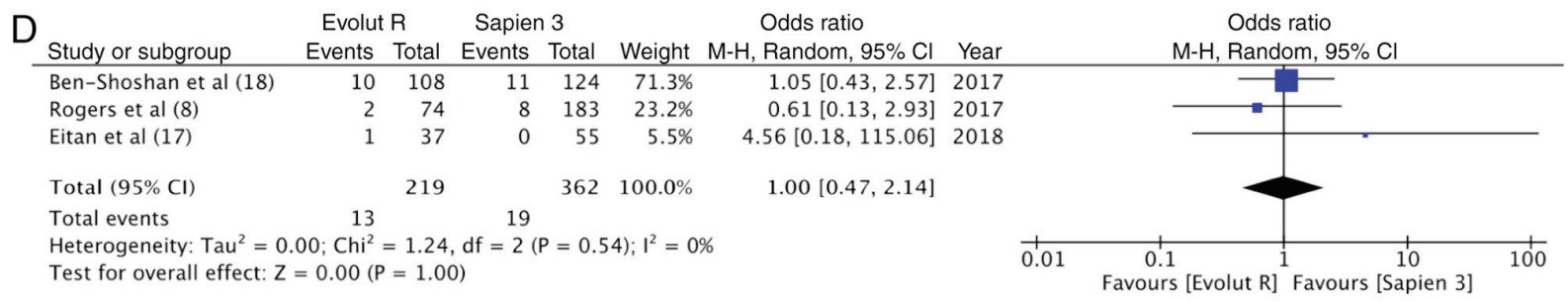

\begin{tabular}{|c|c|c|c|c|c|c|c|c|c|c|c|}
\hline \multirow{2}{*}{$\mathrm{E}_{\text {Study or subgroup }}$} & \multicolumn{2}{|c|}{ Evolut $R$} & \multicolumn{2}{|c|}{ Sapien 3} & \multicolumn{3}{|c|}{ Odds ratio } & \multirow{2}{*}{\multicolumn{4}{|c|}{$\begin{array}{l}\text { Odds ratio } \\
\mathrm{M}-\mathrm{H}, \text { Random, } 95 \% \mathrm{Cl}\end{array}$}} \\
\hline & Events & Total & Events & Total & Weight & $\mathrm{M}-\mathrm{H}$, Random, $95 \% \mathrm{Cl}$ & Year & & & & \\
\hline Rogers et al (8) & 1 & 74 & 4 & 183 & $42.5 \%$ & $0.61[0.07,5.58]$ & 2017 & & =- & & \\
\hline Ben-Shoshan et al (18) & 2 & 108 & 1 & 124 & $35.5 \%$ & $2.32[0.21,25.95]$ & 2017 & & & $\longrightarrow$ & \\
\hline Eitan et al (17) & 2 & 37 & 0 & 55 & $22.0 \%$ & $7.82[0.36,167.62]$ & 2018 & & & & \\
\hline Total $(95 \% \mathrm{Cl})$ & & 219 & & 362 & $100.0 \%$ & $1.72[0.41,7.26]$ & & & & & \\
\hline Total events & 5 & & 5 & & & & & & & & \\
\hline $\begin{array}{l}\text { Heterogeneity: } \operatorname{Tau}^{2}=0 \\
\text { Test for overall effect: } Z\end{array}$ & $\begin{array}{l}00 ; \mathrm{Chi}^{2}= \\
=0.74(\mathrm{P}\end{array}$ & $\begin{array}{l}=1.84, \\
=0.46\end{array}$ & $\mathrm{df}=2$ & $=0.4$ & o, & & & 0.01 & $\begin{array}{cc}0.1 & 1 \\
\text { Favours [Evolut R] }\end{array}$ & $\begin{array}{c}10 \\
\text { Favours [Sapien 3] }\end{array}$ & 100 \\
\hline
\end{tabular}

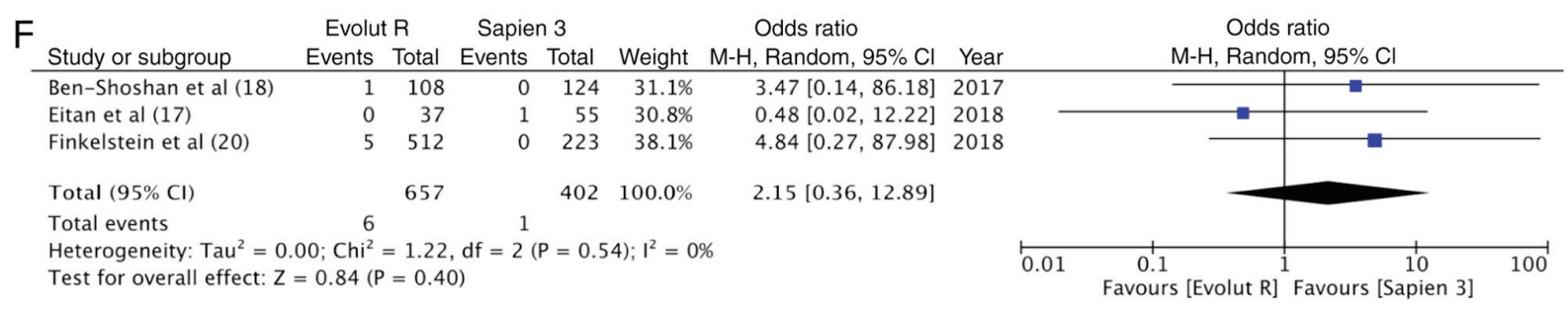

Figure 4. (A) Forrest plot of immediate post-procedural life-threatening bleed. (B) Forrest plot of immediate post-procedural major vascular complication. (C) Forrest plot of immediate post-procedural pacemaker implantation. (D) Forrest plot of immediate post-procedural acute kidney injury. (E) Forrest plot of immediate post-procedural stroke. (F) Forrest plot of immediate post-procedural mortality.

All included studies reported outcomes based on the VARC-2 guidelines (21), which enabled the pooling of multiple variables. Device success rates, defined as the absence of procedural mortality, correct positioning of the valve, no prosthesis- patient mismatch, mean aortic valve gradient $<20 \mathrm{mmHg}$ or peak velocity
$<3 \mathrm{~m} / \mathrm{sec}$, and no moderate or severe prosthetic valve regurgitation (21), were reported by all 5 studies. Our analysis revealed high rates of success with both devices, with no statistically significant difference between the 2 groups. These results are similar to studies comparing the former generation Sapien/Sapien XT and 


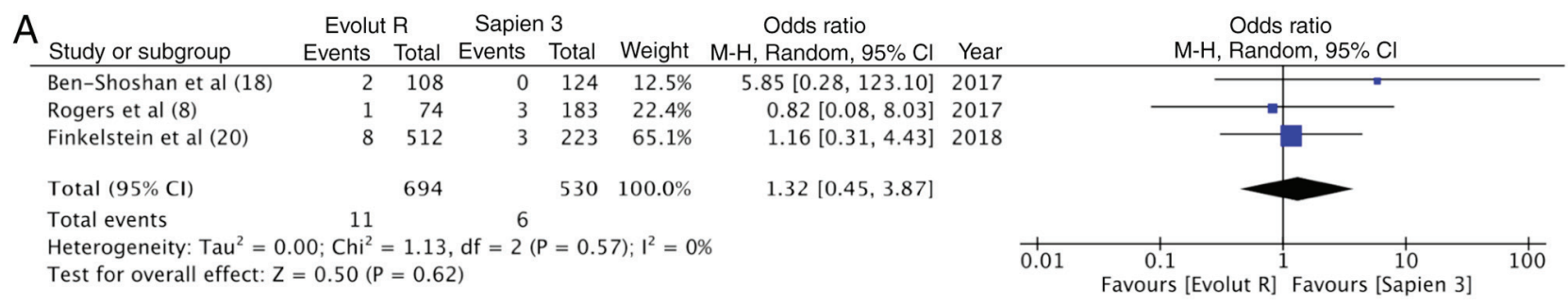

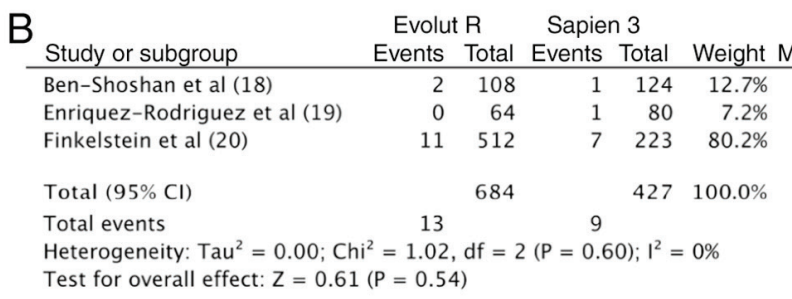

Odds ratio , Random, $95 \% \mathrm{Cl}$ Year $2.32[0.21,25.95] 2017$ $0.41[0.02,10.26] 2018$ $0.68[0.26,1.77] 2018$ $0.76[0.32,1.81]$

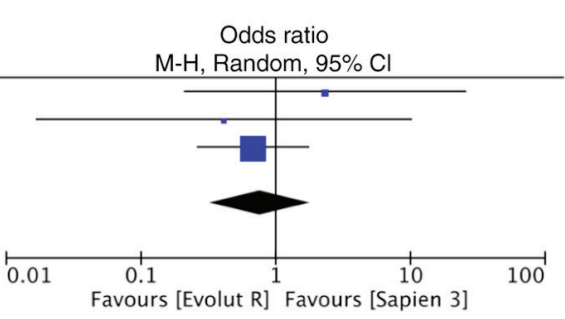

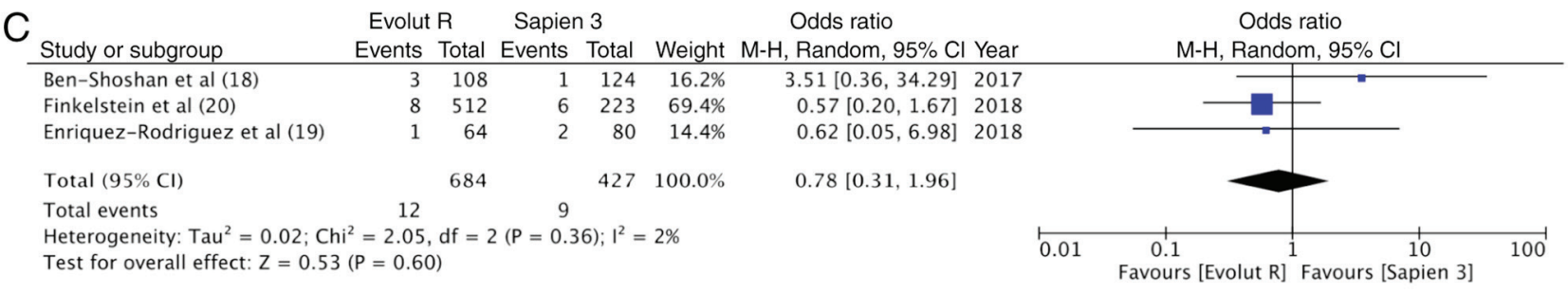

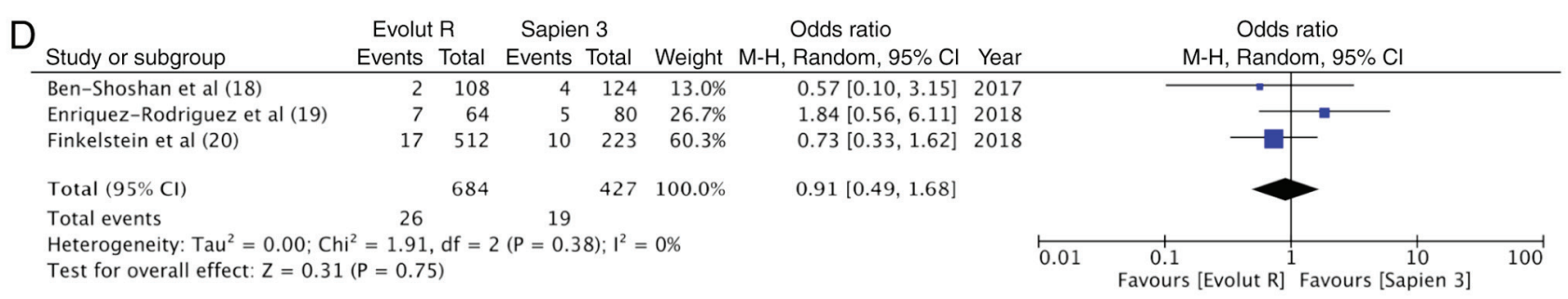

Figure 5. (A) Forrest plot of 30-day mortality. (B) Forrest plot of 30-day stroke. (C) Forrest plot of 30-day life threatening bleed. (D) Forrest plot of 30-day major vascular complication.

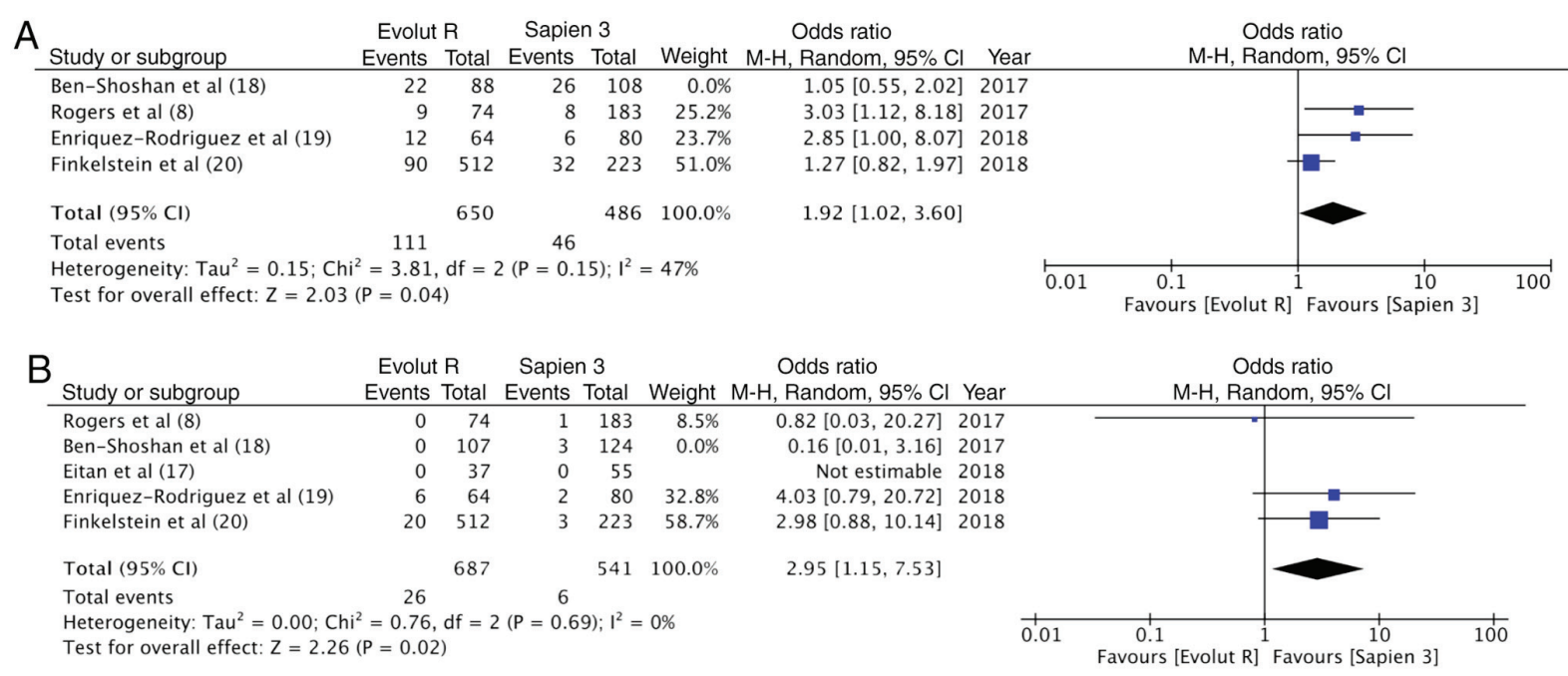

Figure 6. (A) Forrest plot for sensitivity analysis of immediate post-procedural pacemaker implantation. (B) Forrest plot for sensitivity analysis of paravalvular leakage (moderate to severe).

CoreValve devices, which too were comparable in terms of device success $(4,22)$. Pooled device success rates from our analysis are also proportional with single arm trials. Kalra et al (23) reported a $91.3 \%$ success rate in 264 consecutive Evolut $\mathrm{R}$ implantations, while Husser et al (24) reported a success rate of $97.6 \%$ with Sapien 3 valve in 244 patients. 
A significant complication of TAVI is para-valvular leak that can lead to increased mortality for both the balloon-expandable and the self-expanding transcatheter heart valves (25). A meta-analysis of 12,926 patients by Athappan et al reported a $11.7 \%$ incidence of moderate to severe aortic regurgitation in patients treated with the earlier generation Sapien or CoreValve devices (6). To overcome this drawback, newer generation Evolut $\mathrm{R}$ and Sapien 3 valves were developed. These devices are equipped with features for repositionability and retrievability that allow for controlled deployment. While the Evolut $\mathrm{R}$ is equipped with a longer porcine pericardial sealing skirt, the Sapien 3 consists of an outer polyethylene terephthalate cuff to reduce paravalvular regurgitation $(9,26)$. Researchers have reported up to a $50 \%$ reduction in moderate to severe paravalvular leak with Evolut R, as compared to its predecessor, the CoreValve (27). Moderate to severe para-valvular leak has reduced from $6.9 \%$ with SAPIEN XT to $1.6 \%$ with Sapien 3 (28). In this study, the incidence of moderate to severe paravalvular leak was found to be extremely low with a pooled frequency of $3.3 \%$ in the Evolut $\mathrm{R}$ group and $1.4 \%$ in the Sapien 3 group. The statistically significant differences between the 2 devices for this variable, are however, not clear. Finkelstein et al (20) found a higher rate of moderate to severe paravalvular leak in their cohort of Evolut $\mathrm{R}$ patients. The difference was significant for the angiographic outcome and only numerically higher for the echocardiography outcome. The only case-matched study (19) in this review also reported a significantly increased incidence of moderate paravalvular leak with Evolut R. The lower rate of regurgitation with Sapien 3 was attributed to the valves' greater radial force and its adaptability to the aortic annulus (19). Robust evidence on the actual difference between the 2 valves can only be ascertained with prospective studies where the 2 groups are matched for annulus diameter, valve size and valve calcification and outcomes assessed at a central independent echocardiographic core laboratory.

The difference in the hemodynamic performance of the earlier generation Sapien and CoreValve is well documented. In a case-matched study, the self-expanding CoreValve was associated with a significantly lower residual gradient as compared to the Sapien Valve (29). Similar to their predecessors, our results indicate superior antegrade hemodynamic performance of Evolut R as compared to the Sapien 3 device. The difference is probably attributed to the supra-annular position of the Evolut $\mathrm{R}$ leaflets, allowing lower resistance to the left ventricle outflow and gradients (19).

Pacemaker implantation following TAVI varies across studies and can be affected by institutional electrophysiology protocols $(30,31)$. Single arm studies report the incidence of permanent pacemaker implantation with Evolut $\mathrm{R}$ to be $16.4-19.7 \%(23,26)$. Similarly, $14-17 \%$ of patients require permanent pacemaker implantation with Sapien 3 device $(9,24)$. In this study, the pooled incidence of pacemaker implantation with Evolut R was slightly higher at $18 \%$ as compared to $12 \%$ with the Sapien 3 device. While the difference was not statistically significant, evidence in not strong since sensitivity analysis presented conflicting results. The additional skirt added to Sapien 3 device, to reduce paravalvular leakage, has been associated with increased need of post-procedural pacemaker implantation. It is postulated that higher local trauma delivered to the conduction system with this addition results in greater requirement for pacemaker implantation $(20,32)$. On the contrary, the re-sheathable delivery system of the Evolut-R may allow more accurate valve positioning, potentially reducing trauma to the conduction system. More studies are required to validate the comparison.

Vascular complications following TAVI is another major problem, with initial rates of complications ranging from 1.9 to $17.3 \%$ (33). Important predictors are small vessel diameters, presence of severe calcifications and sheath-to-femoral artery ratio (33). Important changes in the design of the newer generation valves have been made. The 14F expandable sheath with Sapien 3 and the lower profile 14F equivalent sheath with the Evolut $\mathrm{R}$ device have significantly reduced the incidence of major vascular complications as compared to the earlier generation valves $(23,24)$. Our review found that the incidence of major vascular complications and life-threatening bleeds with both devices to be extremely low and comparable.

The short-term mortality rates with earlier generation self-expanding and balloon-expanding valves have been reported to be 6.8 and $7.1 \%$, respectively (34). These rates have significantly improved with both new-generation devices. The overall pooled 30-day mortality rates was found to be very low with no difference between Evolut R and Sapien 3 (1.6 vs. $1.1 \%$ ). 30-day stroke outcomes also did not differ between the two devices.

The limitations of this study need to be enumerated. Firstly, this is a meta-analysis of retrospective observational studies. An inherent drawback of observational studies is a greater probability of bias as compared to randomized controlled trials. Secondly, this is a study-level meta-analysis, a patient level meta-analysis would have provided stronger evidence. Thirdly, the participants of the 2 groups were not matched for all baseline characteristics. Only one-study included case-matched participants. The results of this analysis, therefore, must be interpreted with caution. Fourthly, only short-term outcomes were compared as long-term data was not available. Lastly, not all studies utilized transfemoral route in all patients. The use of other routes would have introduced bias in the results.

Despite the limitations, the consistency of the direction and magnitude of the overall effect, and stability of the results after sensitivity analysis, provide some support to the study's overall conclusions. To the best of our knowledge, this is the first systematic review and meta-analysis comparing the Evolut R and Sapien 3 device. Our results indicate, Evolut R and Sapien 3 valves may be comparable in terms of device success and short-term complications. The difference between the 2 devices for post-operative moderate to severe paravalvular leak and permanent pacemaker implantation is not clear. There is a need for a large multi-center randomized controlled trial to provide stronger evidence on this subject.

\section{Acknowledgements}

Not applicable.

\section{Funding}

No funding was received. 


\section{Availability of data and materials}

The datasets used and/or analyzed during the current study are available from the corresponding author on reasonable request.

\section{Authors' contributions}

$\mathrm{CH}$ and $\mathrm{JL}$ designed the paper. $\mathrm{CH}$ and $\mathrm{LX}$ were involved in literature search and data interpreted. JL was responsible for the data analysis. $\mathrm{CH}$ and LX prepared the manuscript. JL edited the manuscript. All authors have read and approved the final manuscript. All authors have read and approved the final manuscript.

\section{Ethical approval and consent to participate}

Not applicable.

\section{Patient consent for publication}

Not applicable.

\section{Competing interests}

The authors declare that they have no competing interests.

\section{References}

1. Smith CR, Leon MB, Mack MJ, Miller DC, Moses JW, Svensson LG, Tuzcu EM, Webb JG, Fontana GP, Makkar RR, et al: Transcatheter versus surgical aortic-valve replacement in high-risk patients. N Engl J Med 364: 2187-2198, 2011.

2. Adams DH, Popma JJ, Reardon MJ, Yakubov SJ, Coselli JS, Deeb GM, Gleason TG, Buchbinder M, Hermiller J Jr, Kleiman NS, et al: Transcatheter aortic-valve replacement with a self-expanding prosthesis. N Engl J Med 370: 1790-1798, 2014.

3. Collas VM, Dubois C, Legrand V, Kefer J, De Bruyne B, Dens J, Rodrigus IE, Herijgers P, Bosmans JM and Belgian TAVI Registry Participants: Midterm clinical outcome following Edwards SAPIEN or Medtronic Corevalve transcatheter aortic valve implantation (TAVI): Results of the Belgian TAVI registry. Catheter Cardiovasc Interv 86: 528-535, 2015.

4. Chieffo A, Buchanan GL, Van Mieghem NM, Tchetche D, Dumonteil N, Latib A, van der Boon RM, Vahdat O, Marcheix B, Farah B, et al: Transcatheter aortic valve implantation with the Edwards SAPIEN versus the medtronic CoreValve revalving system devices. J Am Coll Cardiol 61: 830-836, 2013.

5. Van Belle E, Juthier F, Susen S, Vincentelli A, Iung B, Dallongeville J, Eltchaninoff H, Laskar M, Leprince P, Lievre $\mathrm{M}$, et al: Postprocedural aortic regurgitation in balloon-expandable and self-expandable transcatheter aortic valve replacement procedures: Analysis of predictors and impact on long-term mortality: Insights from the FRANCE2 registry. Circulation 129: 1415-1427, 2014.

6. Athappan G, Patvardhan E, Tuzcu EM, Svensson LG, Lemos PA, Fraccaro C, Tarantini G, Sinning JM, Nickenig G, Capodanno D, et al: Incidence, predictors, and outcomes of aortic regurgitation after transcatheter aortic valve replacement: Meta-analysis and systematic review of literature. J Am Coll Cardiol 61: 1585-1595, 2013.

7. Grover FL, Vemulapalli S, Carroll JD, Edwards FH, Mack MJ, Thourani VH, Brindis RG, Shahian DM, Ruiz CE, Jacobs JP, et al: 2016 annual report of the society of thoracic surgeons/American college of cardiology transcatheter valve therapy registry. Ann Thorac Surg 103: 1021-1035, 2017.

8. Rogers T, Steinvil A, Buchanan K, Alraies MC, Koifman E, Gai J, Torguson R, Okubagzi P, Ben-Dor I, Pichard A, et al: Contemporary transcatheter aortic valve replacement with third-generation balloon-expandable vs. self-expanding devices. J Interv Cardiol 30: 356-361, 2017.
9. Binder RK, Rodés-Cabau J, Wood DA, Mok M, Leipsic J, De Larochellière R, Toggweiler S, Dumont E, Freeman M, Willson AB and Webb JG: Transcatheter aortic valve replacement with the SAPIEN 3: A new balloon-expandable transcatheter heart valve. JACC Cardiovasc Interv 6: 293-300, 2013

10. Manoharan G, Walton AS, Brecker SJ, Pasupati S, Blackman DJ, Qiao H and Meredith IT: Treatment of symptomatic severe aortic stenosis with a novel resheathable supra-annular self-expanding transcatheter aortic valve system. JACC Cardiovasc Interv 8: 1359-1367, 2015.

11. Schulz E, Jabs A, Gori T, von Bardeleben S, Hink U, Kasper-König W, Vahl CF and Münzel T: Transcatheter aortic valve implantation with the new-generation Evolut $\mathrm{R}^{\mathrm{TM}}$ : Comparison with CoreValve ${ }^{\circledR}$ in a single center cohort. Int $\mathrm{J}$ Cardiol Heart Vasc 12: 52-56, 2016.

12. Nijhoff F, Abawi M, Agostoni P, Ramjankhan FZ, Doevendans PA and Stella PR: Transcatheter aortic valve implantation with the new balloon-expandable Sapien 3 versus Sapien XT valve system: A propensity score-matched single-center comparison. Circ Cardiovasc Interv 8: e002408, 2015.

13. Stroup DF, Berlin JA, Morton SC, Olkin I, Williamson GD, Rennie D, Moher D, Becker BJ, Sipe TA and Thacker SB: Meta-analysis of Observational Studies in epidemiology: A proposal for reporting. Meta-analysis Of observational studies in epidemiology (MOOSE) group. JAMA 283: 2008-2012, 2000.

14. Wells GA, Shea B, O'Connell D, Peterson J, Welch V, Losos M and Tugwell P: The Newcastle-Ottawa Scale (NOS) for assessing the quality of nonrandomised studies in meta-analyses. Ottawa Hospital Research Institute, Ottawa, ON, 2013. http://www.ohri. ca/programs/clinical_epidemiology/oxford.asp.

15. Tham JLM, Adams H, Paleri S, Wright C, Dimitriou J, Newcomb A, MacIsaac AI, Whitbourn RJ and Palmer SC: Clinical outcomes of self-expandable vs. balloon-expandable TAVI for severe aortic stenosis. Acta Cardiol: Apr 1, 2019 (Epub ahead of print).

16. Wang TY, Gracia E, Callahan S, Bilfinger T, Tannous H, Pyo R, Kort S, Skopicki H, Weinstein J, Patel N, et al: Gender disparities in management and outcomes following transcatheter aortic valve implantation with newer generation transcatheter valves. Am J Cardiol 123: 1489-1493, 2019.

17. Eitan A, Witt J, Stripling J, Haselbach T, Rieß FC and Schofer J: Performance of the Evolut-R $34 \mathrm{~mm}$ versus Sapien-3 $29 \mathrm{~mm}$ in Transcatheter aortic valve replacement patients with larger annuli: Early outcome results of Evolut- $\mathrm{R} 34 \mathrm{~mm}$ as compared with Sapien-3 $29 \mathrm{~mm}$ in patients with Annuli $\geq 26 \mathrm{~mm}$. Catheter Cardiovasc Interv 92: 1374-1379, 2018.

18. Ben-Shoshan J, Konigstein M, Zahler D, Margolis G, Chorin E, Steinvil A, Arbel Y, Aviram G, Granot Y, Barkagan M, et al: Comparison of the Edwards SAPIEN S3 versus medtronic Evolut-R devices for transcatheter aortic valve implantation. Am J Cardiol 119: 302-307, 2017.

19. Enríquez-Rodríguez E, Amat-Santos IJ, Jiménez-Quevedo P, Martín-Morquecho I, Tirado-Conte G, Pérez-Vizcayno MJ, Gómez de Diego JJ, Arnold R, Aldazábal A, Rojas P, et al: Comparison of the hemodynamic performance of the balloon-expandable SAPIEN 3 versus self-expandable Evolut $\mathrm{R}$ transcatheter valve: A case-matched study. Rev Esp Cardiol (Engl Ed) 71: 735-742, 2018 (In English, Spanish).

20. Finkelstein A, Steinvil A, Rozenbaum Z, Halkin A, Banai S, Barbash I, Guetta V, Segev A, Danenberg H, Orvin K, et al: Efficacy and safety of new-generation transcatheter aortic valves: insights from the Israeli transcatheter aortic valve replacement registry. Clin Res Cardiol 108: 430-437, 2019.

21. Kappetein AP, Head SJ, Généreux P, Piazza N, van Mieghem NM, Blackstone EH, Brott TG, Cohen DJ, Cutlip DE, van Es GA, et al: Updated standardized endpoint definitions for transcatheter aortic valve implantation: The valve academic research Consortium-2 consensus document (VARC-2). Eur J Cardiothorac Surg 42: S45-S60, 2012.

22. Zhang Y, Pyxaras SA, Wolf A, Schmitz T and Naber CK: Propensity-matched comparison between direct flow medical, medtronic corevalve, and Edwards Sapien XT prostheses: Device success, thirty-day safety, and mortality. Catheter Cardiovasc Interv 85: 1217-1225, 2015.

23. Kalra SS, Firoozi S, Yeh J, Blackman DJ, Rashid S, Davies S, Moat N, Dalby M, Kabir T, Khogali SS, et al: Initial experience of a second-generation self-expanding transcatheter aortic valve: The UK \& Ireland Evolut R implanters' registry. JACC Cardiovasc Interv 10: 276-282, 2017. 
24. Husser O, Pellegrini C, Kessler T, Burgdorf C, Thaller H Mayr NP, Ott I, Kasel AM, Schunkert H, Kastrati A and Hengstenberg C: Outcomes after transcatheter aortic valve replacement using a novel balloon-expandable transcatheter heart valve: A single-center experience. JACC Cardiovasc Interv 8: 1809-1816, 2015

25. Moretti C, D'Ascenzo F, Mennuni M, Taha S, Brambilla N, Nijhoff F, Fraccaro C, Barbanti M, Tamburino C, Tarantini G, et al: Meta-analysis of comparison between self-expandable and balloon-expandable valves for patients having transcatheter aortic valve implantation. Am J Cardiol 115: 1720-1725, 2015.

26. Popma JJ, Reardon MJ, Khabbaz K, Harrison JK, Hughes GC, Kodali S, George I, Deeb GM, Chetcuti S, Kipperman R, et al: Early clinical outcomes after transcatheter aortic valve replacement using a novel self-expanding bioprosthesis in patients with severe aortic stenosis who are suboptimal for surgery: Results of the Evolut R U.S. study. JACC Cardiovasc Interv 10: 268-275, 2017.

27. Kowalewski M, Gozdek M, Raffa GM, Słomka A, Zieliński K, Kubica J, Anisimowicz L, Kowalewski J, Landes U, Kornowski R, et al: Transcathether aortic valve implantation with the new repositionable self-expandable Medtronic Evolut R vs. CoreValve system: Evidence on the benefit of a meta-analytical approach. J Cardiovasc Med (Hagerstown) 20: 226-236, 2019.

28. Ando T, Briasoulis A, Holmes AA, Taub CC, Takagi H and Afonso L: Sapien 3 versus Sapien XT prosthetic valves in transcatheter aortic valve implantation: A meta-analysis. Int J Cardiol 220: 472-478, 2016.

29. Nombela-Franco L, Ruel M, Radhakrishnan S, Webb JG, Hansen M, Labinaz M, Thompson C, Fremes S, Dumont E, DeLarochellière $\mathrm{R}$, et al: Comparison of hemodynamic performance of self-expandable CoreValve versus balloon-expandable Edwards SAPIEN aortic valves inserted by catheter for aortic stenosis. Am J Cardiol 111: 1026-1033, 2013.
30. Khawaja MZ, Rajani R, Cook A, Khavandi A, Moynagh A, Chowdhary S, Spence MS, Brown S, Khan SQ, Walker N, et al: Permanent pacemaker insertion after CoreValve transcatheter aortic valve implantation: Incidence and contributing factors (the UK CoreValve collaborative). Circulation 123: 951-960, 2011.

31. Biner S, Michowitz Y, Leshem-Rubinow E, Topilsky Y, Ben-Assa E, Shimiaie J, Banai S, Keren G, Steinvil A and Finkelstein A: Hemodynamic impact and outcome of permanent pacemaker implantation following transcatheter aortic valve implantation. Am J Cardiol 113: 132-137, 2014.

32. Webb J, Gerosa G, Lefèvre T, Leipsic J, Spence M, Thomas M, Thielmann M, Treede H, Wendler O and Walther T: Multicenter evaluation of a next-generation balloon-expandable transcatheter aortic valve. J Am Coll Cardiol 64: 2235-2243, 2014.

33. Toggweiler S, Leipsic J, Binder RK, Freeman M, Barbanti M, Heijmen RH, Wood DA and Webb JG: Management of vascular access in transcatheter aortic valve replacement: Part 2: Vascular complications. JACC Cardiovasc Interv 6: 767-776, 2013.

34. Agarwal S, Parashar A, Kumbhani DJ, Svensson LG, Krishnaswamy A, Tuzcu EM and Kapadia SR: Comparative meta-analysis of balloon-expandable and self-expandable valves for transcatheter aortic valve replacement. Int J Cardiol 197: 87-97, 2015.

This work is licensed under a Creative Commons Attribution-NonCommercial-NoDerivatives 4.0 International (CC BY-NC-ND 4.0) License. 